\title{
Ascending Projections of Simple and Complex Cells in Layer 6 of the Cat Striate Cortex
}

\author{
Judith A. Hirsch, Christine A. Gallagher, José-Manuel Alonso, and Luis M. Martinez \\ Laboratory of Neurobiology, The Rockefeller University, New York, New York 10021
}

Receptive field properties vary systematically across the different layers of the cat striate cortex. Understanding how these functional differences emerge requires a precise description of the interlaminar connections and the quality of information that they transmit. This study examines the contribution of the two physiological types of neuron in layer 6 , simple and complex, to the cortical microcircuit. The approach was to make whole-cell recordings with dye-filled electrodes in vivo to correlate visual response property with intracortical projection pattern. The two simple cells we stained projected to layer 4, as previously reported (Gilbert and Wiesel, 1979; Martin and Whitteridge, 1984). Six of the eight complex cells that we labeled projected to the superficial layers, a pathway not previously described in the cat. The remaining two cells targeted the infragranular layers. Layer 4 is dominated by simple cells, whereas layers 5 and $2+3$ are mainly composed of complex cells (Hubel and Wiesel, 1962; Gilbert, 1977). Hence, our results indicate that the ascending projections of simple cells in layer 6 target other simple cells. In parallel, the ascending projections of a population of complex cells in layer 6 favor other complex cells. Anatomical experiments in several species (Lund and Boothe, 1975; Burkhalter, 1989; Usrey and Fitzpatrick, 1996; Wiser and Callaway, 1996) had also demonstrated that layer 6 gives rise to two separate intracortical pathways. Pooling the results of these anatomical studies with our own suggests a common feature of the laminar organization: cells that project to different intracortical targets have distinct functional characteristics.

Key words: visual cortex; patch recording in vivo; simple cell; complex cell; layer 6; pyramidal cell
We are interested in how visual information is coded by the different elements of the cortical microcircuit. With the striking exception of layer 6, each layer in the cat striate cortex is mainly composed of one physiological cell type, simple or complex (Hubel and Wiesel, 1962; Gilbert, 1977; Gilbert and Wiesel, 1981; Grieve and Sillito, 1995; see Fig. 6). Simple cells dominate layer 4, the principal target of the lateral geniculate nucleus; their receptive fields are built of adjacent subregions arranged so that neighbors prefer stimuli of the opposite contrast (Hubel and Wiesel, 1962; Gilbert, 1977). The laminae that receive little input from the thalamus, layer $2+3$, and layer 5, are largely composed of complex cells, neurons whose receptive fields lack spatially separate subregions (Hubel and Wiesel, 1962; Gilbert, 1977). Layer 6 is divided into two tiers, as distinguished by the pattern of thalamic innervation (LeVay and Gilbert, 1976). The upper stratum receives appreciable contact from the geniculate and contains a mix of simple and complex cells. The lower aspect derives its chief input from intracortical sources and is populated by complex cells (Hubel and Wiesel, 1962; Gilbert, 1977; Grieve and Sillito, 1995).

Received May 28, 1998; revised July 21, 1998; accepted July 22, 1998.

This work was supported by National Institutes of Health Grants EY09593 (J.A.H.) and EY05253 (T.N.W.), the Klingenstein Fund (J.A.H.), and the Human Frontiers Science Program Organization (L.M.M.). We are grateful to Torsten N. Wiesel for support and advice during all phases of the project. We thank R. Clay Reid for contributing the software to generate the visual stimuli and to view the intracellular records. Kathleen McGowan, Johanna L. Kornblum, and Komal A. Desai provided superb technical support and helped to reconstruct some of the labeled neurons. Peter Peirce photographed the drawings patiently and precisely. We are indebted to W. Martin Usrey for advice in early stages of the project and for his many thoughtful criticisms of this manuscript.

Correspondence should be addressed to Judith A. Hirsch, Box 138, Laboratory of Neurobiology, The Rockefeller University, 1230 York Avenue, New York, NY 10021.

Copyright (ㄷ) 1998 Society for Neuroscience $\quad 0270-6474 / 98 / 188086-09 \$ 05.00 / 0$
In keeping with their physiological uniformity, layers $2+3,4$, and 5 each have one principal laminar target. Layer 4 projects to $2+3$, which directs its output to layer 5; layer 5, in turn, projects to layer 6 (Gilbert and Kelly, 1975; Gilbert and Wiesel, 1979; Lin et al., 1979; Martin and Whitteridge, 1984; McGuire et al., 1984). Based on the projection patterns of just a handful of labeled cells in layer 6 in vivo, it was thought that the entire interlaminar output was directed to layer 4 . We have characterized the receptive field structure and projection pattern of simple and complex cells throughout the depth of layer 6. The approach was to combine whole-cell recording with intracellular staining in vivo. The simple cells we labeled targeted layer 4, as previously reported (Gilbert and Wiesel, 1979; Martin and Whitteridge, 1984). By contrast, the complex cells we stained had a different projection pattern. These directed the bulk of their output to the laminae composed of complex cells, layers 5 and $2+3$, rather than to layer 4 . Thus, a population of complex cells in layer 6 provides an ascending projection to the superficial layers distinct from the path that leads from layer 6 to layer 4 .

\section{MATERIALS AND METHODS}

Anesthesia. Nine adult cats, $2.5-3.5 \mathrm{~kg}$, were anesthetized with ketamine $(10 \mathrm{mg} / \mathrm{kg}$, i.m.) followed by thiopental sodium $(20 \mathrm{mg} / \mathrm{kg}$, i.v.), supplemented as needed. Lidocaine was applied topically at all incisions or points of pressure. Temperature $\left(37^{\circ}-38^{\circ} \mathrm{C}\right), \mathrm{EKG}, \mathrm{EEG}$, and expired $\mathrm{CO}_{2}(27-33 \mathrm{mmHg})$ were monitored throughout the experiment. Anesthesia was maintained by continuous infusion of thiopental sodium (2-4 $\mathrm{mg} \cdot \mathrm{kg} \cdot \mathrm{hr}$, i.v.) adjusted as indicated by the EEG and EKG. After the completion of surgery, animals were paralyzed [vecuronium bromide (Norcuron) $0.2 \mathrm{mg} \cdot \mathrm{kg} \cdot \mathrm{hr}$, i.v.] and respired artificially.

Surgery. An endotracheal tube was introduced through a tracheotomy before the animal was placed in a stereotaxic apparatus. Then, a cortical craniotomy centered on Horsley-Clark coordinates P3-L2 was made to expose the longitudinal gyrus. After dilating the pupils (1\% atropine sulfate) and retracting the nictitating membranes (10\% phenylephrine), 
the eyes were refracted and fitted with contact lenses to focus on a tangent screen. The position of the area centralis and the optic disk of each eye was determined with a fundus camera. Before recording, the dura was reflected, and the cortex was covered with agarose.

Acquisition of visually evoked responses. Intracellular and extracellular records were collected by a computer running the Discovery software package (Datawave Systems, Longmont, CO); intracellular records were normally sampled at 3-4 kHz. An AT-vista board (Truevision, Indianapolis, IN), controlled by the same computer that received the data, generated visual stimuli that were presented on a computer monitor (frame rate, 100, 105, 128, or $140 \mathrm{~Hz}$ ). Each cycle of the stimulus protocol consisted of light or dark squares at various contrasts (range, 30-70\%) flashed singly for 29-39 msec in pseudorandom order, 16 times on a $16 \times$ 16 grid (sparse noise; Jones and Palmer, 1987). Grid spacing ranged from 0.4 to $0.85^{\circ}$ and square size from 0.4 to $1.7^{\circ}$.

Determination of receptive fields. Depolarizations evoked by bright stimuli were termed "on" responses and those to dark stimuli, "off" responses. Receptive fields with separate and adjacent on and off subregions were classified as simple; those that lacked segregated on and off responses were considered complex (Hubel and Wiesel, 1962; for review, see Skottun et al., 1991). To generate maps of the simple receptive fields, responses to dark stimuli were subtracted from bright ones. For complex cells, separate maps of bright and dark responses were made. All fields shown were smoothed by one half pixel.

Recording. Patch-pipette resistance was $\geq 12 \mathrm{M} \Omega$ when filled with internal solution, in mM: $\mathrm{K}$ gluconate, $120 ; \mathrm{NaCl}, 5 ; \mathrm{CaCl}_{2}, 1 ; \mathrm{MgCl}_{2}, 1$; EGTA, 11; GTP, 0.2; ATP, 2; HEPES, 40; and biocytin 1\%, pH 7.3, 290 mOsm (Malinow and Tsien, 1990). Initial seal resistances were 0.5-1.0 G $\Omega$. Recordings were made with an Axopatch 200A amplifier (Axon Instruments, Foster City, CA) and stored as described above; neither capacitance nor access resistance was compensated, so fast spikes were filtered. Because the access resistance often increased after rupture of the membrane (Edwards and Konnerth, 1992), the voltages recorded were sometimes divided (Stühmer et al., 1983).

Histology. After histological processing (Horikawa and Armstrong, 1988; Hirsch, 1995), labeled neurons were drawn using a camera lucida, or a computerized three-dimensional reconstruction system, (MicroBrightfield, Colchester, VT).

\section{RESULTS}

\section{Physiological differences between simple and complex cells in layer 6}

The response patterns of simple cells and complex cells are illustrated in Figure 1. Simple receptive fields comprise adjacent on and off subregions; within each subregion stimuli of reverse contrast evoke responses of the opposite sign (Hubel and Wiesel, 1962; Jones and Palmer, 1987; Ferster, 1988, Hirsch et al., 1995). Postsynaptic responses to stimuli flashed within the on subregion of a layer 6 simple cell are shown in Figure $1 A$; the receptive field map above the traces indicates stimulus position. Each presentation of a bright square evoked a strong depolarization; a slight hyperpolarization and excitatory rebound followed the withdrawal of the stimulus. Dark squares elicited a hyperpolarization followed by an excitatory rebound. Responses from the off subregion were similar except that dark stimuli were excitatory, and the bright ones were inhibitory (data not shown). This "pushpull" pattern of response is also common to simple cells in layer 4 and its borders (Hirsch et al., 1995).

Although complex receptive fields are far more varied than those of simple cells (Hubel and Wiesel, 1962; Gilbert, 1977; Movshon et al., 1978; Palmer and Davis, 1981; Ohzawa and Freeman, 1986), they share a common characteristic: their receptive fields are not divided into subregions. The map at the top of Figure $1 B$ shows the field of a complex cell that responded to dark stimuli; these evoked a brief depolarization (Fig. 1B, bottom right). Bright spots were essentially ineffective, with only a faint response to withdrawal of the stimulus (Fig. 1B, bottom left). This sort of response pattern was the most common in our sample (see Figs. $3 A, B, 5 B)$. Variations among cells included responses dom- inated by inhibition rather than excitation (see Fig. $4 A$ ), insensitivity to the flashed stimuli (see Figs. $4 B, 5 A$; fields were mapped with moving bars) or overlapping on and off responses (data not shown). As yet, we have not detected physiological trends that correlate with the different projection patterns of the complex cells that we describe below.

\section{Projections of simple cells}

We found that simple cells in layer 6 had dendrites and axons that arborized densely in layer 4, as previously described (Gilbert and Wiesel, 1979; Martin and Whitteridge, 1984). Maps of the receptive fields are shown above the reconstructions. The cell pictured in Figure $2 A$ was located in middle of layer 6. Its basal dendritic arbor spread densely within $\sim 100 \mu \mathrm{m}$ of the soma; the apical dendrite fanned into long branches that traversed the depth of layer 4. Axonal projections were sparse near layer 6; they became more elaborate as they entered layer 4 to innervate its upper half. A second simple cell sat at the border between layers 5 and 6 (Fig. $2 B$ ). Its basal dendrites were rooted in layer 6; its apical dendrite and its apical arbor split into a few vertical branches in layer 4 . Unlike the neuron in Figure $2 A$, this cell directed horizontal connections in layer 6 . In sum, for simple cells, the dendrites and axons tended to ramify in the vicinity of other simple cells, that is, in regions where the afferents from the dorsal layers (A, A1) of the lateral geniculate terminate (see Fig. 6).

\section{Projections of complex cells}

For the complex cells we labeled, the projection pattern was distinctly different from that for simple cells and demonstrates a novel component of the cortical microcircuit. Instead of ending in layer 4, the complex cells directed the majority of their output to layer $2+3$ or layer 5 . That is, they targeted regions that are populated by other complex cells and that receive input from the ventral (C) layers of the geniculate and extrageniculate nuclei (see Fig. 6). The projection patterns we have observed so far cluster into three groups: cells that favor the lower aspect of layer $2+3$, those preferring the upper tier of layer $2+3$, and those that send stronger projections to the infragranular (layers 5 and 6) than to the supragranular (layer 2+3) layers.

\section{Cells favoring the lower aspect of layers $2+3$}

Two complex cells that directed their output to the lower tier of layer $2+3$ are drawn in Figure 3. The soma of one cell lay at base of the layer (Fig. $3 A$ ); its basal dendrites spread near the soma, with a few reaching into the white matter. The apical dendrite approached layer 1 but did not branch after leaving layer 5 . Axonal arbors remained fairly sparse until reaching the border between layers 4 and $2+3$. There they divided frequently, with most shoots innervating lower layer $2+3$. A second cell with a similar projection pattern is pictured in Figure $3 B$. Its soma also occupied the lower part of the layer. With the exception of a shorter apical process, the dendritic arbor was much like that seen in Figure $3 A$; it avoided regions supplied by the primary afferents. The axon gave off short collaterals in layers 6 and 5 before traveling through layer 4 . As for the cell in Figure $3 A$, axonal branching was densest at the upper border of layer 4 and lower layer $2+3$. A collateral that left the home column formed a separate cluster in the superficial layers. Last, the axons of both of these cells seemed to end in the white matter rather than exiting area 17. 
A

Simple Cell

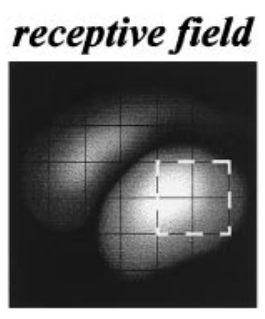

intracellular responses to: bright squares

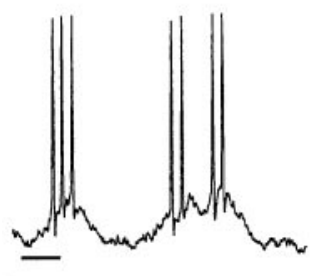

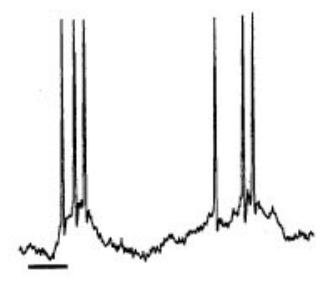

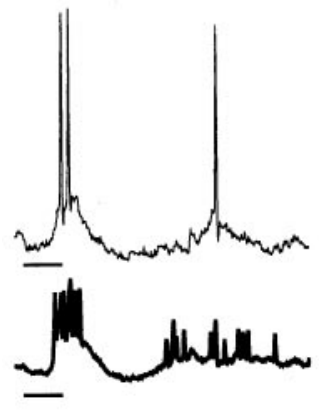

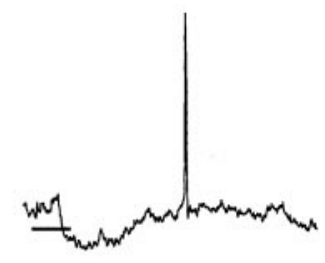

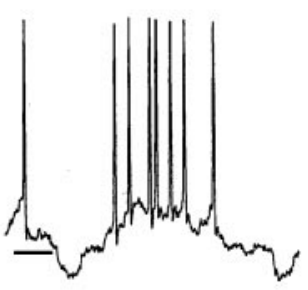

dark squares

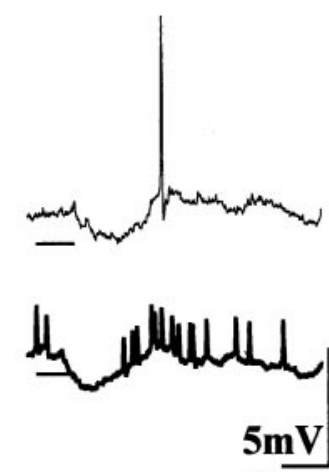

B

Complex Cell receptive field

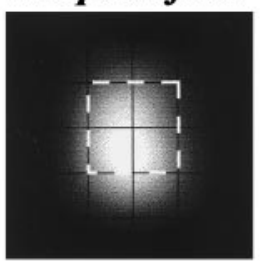

intracellular responses to: bright squares dark squares
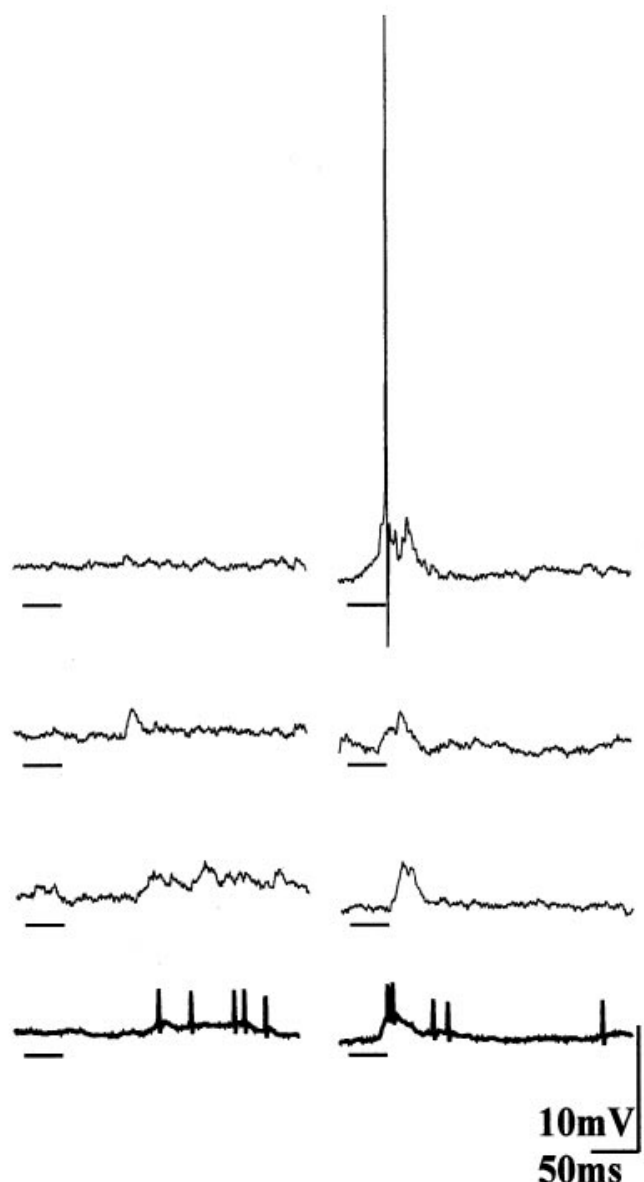

Figure 1. Synaptic responses of simple and complex cells in layer 6. The receptive field of a layer 6 simple cell had a small off subregion left of a stronger on subregion $(A, t o p)$. The dotted square indicates the peak of the on subregion. The left and right panels beneath the map each show three individual trials of a bright or dark stimulus that fell over the peak of the on subregion; the averaged response of all sixteen trials of each stimulus is shown in bold. The thick bar under every trace marks stimulus duration. The essential features of the response pattern are that the bright stimuli initiated a strong depolarization $(A$, bottom left), whereas dark stimuli flashed at the same spot elicited hyperpolarizations $(A$, bottom right $)$. $B$ illustrates responses of a typical complex cell in layer 6 . Its receptive field $(B, t o p)$ was constructed from responses to dark stimuli because bright squares had limited action. The responses evoked by dark squares falling in the peak of the field (dotted square) were small, brief depolarizations $(B$, bottom right). There was no response to the introduction of bright squares, although a weak depolarization occasionally followed stimulus withdrawal $(B$, bottom left $)$.

\section{Cells favoring the upper aspect of layer $2+3$}

Figure $4 A$ shows a striking example of a cell that favored the upper tier of the superficial layers; its soma was near the top of layer 6. The basal dendrites formed a radial array that extended well into layer 5 , and the apical dendrite ended in a compact tuft in layer 1. A dense axonal plexus wove around the basal dendrites, 
$\mathbf{A}$

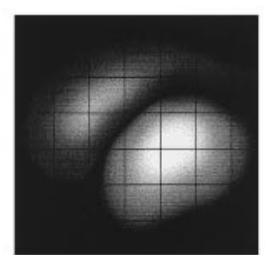

$\overline{1}$

$2+3$

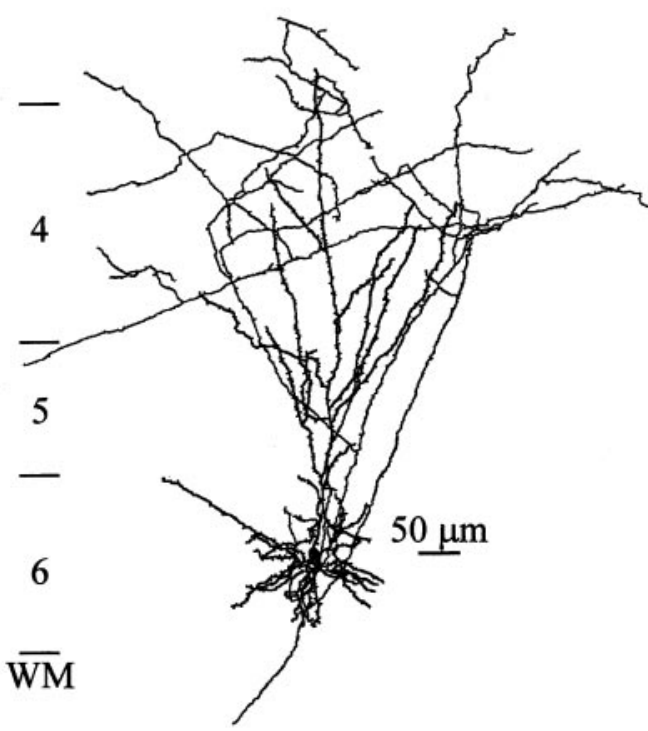

B

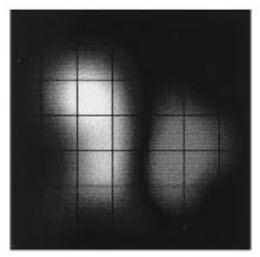

$2+3$

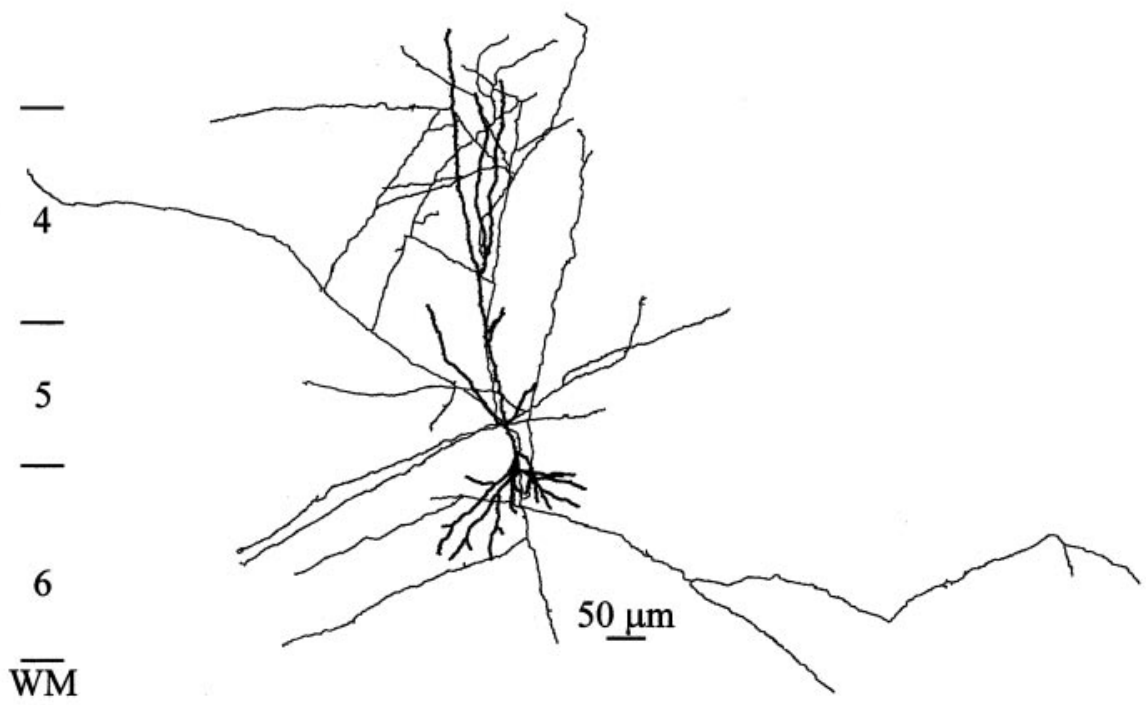

Figure 2. Projections of simple cells in layer 6. The receptive fields of two simple cells are shown above the anatomical reconstructions. The receptive field in panel $\mathrm{A}$ is the same as in Figure $1 \mathrm{~A}$. The cell was located in the middle of layer 6 and projected densely to layer 4 . A second cell had a receptive field comprising a strong off subregion flanked by a weaker on subregion. This cell also projected to layer 4; in addition, it made horizontal connections within layer 6 itself. Both neurons had descending collaterals that appeared to leave area 17. Grid spacing was $0.4^{\circ}$ for $A$ and $0.85^{\circ}$ for $B$.

with several collaterals ascending to layer $2+3$ (one ascending trunk rose only so far as layer 4). Once in the upper half of the superficial layers, these axons split into many short processes that ended within $\sim 100 \mu \mathrm{m}$ of the apical dendrite. The cell also directed a prominent collateral outside of the home column, as in Figure $3 B$. A second cell, located in the middle of the layer, sent local dendrites throughout the laminar depth and into the white matter; its apical dendrite reached the middle of layer $2+3$. Ascending axons loosely spiraled the apical dendrite, sending numerous twigs in layers 6 and 5 and few in lower layer 4. The main collaterals continued on a path to the superficial aspect of layer $2+3$ where they forked into long branches that reached the pia. Two additional cells (data not shown) were located at the bottom of layer 6 and had dendrites that reached layer 1 . One sent a sparse projection that reached layer 1 ; the axon of the other terminated in a thick spray within the upper aspect of layer $2+3$. Three of the four cells had axons that appeared to exit area 17.

\section{Cells favoring infragranular layers}

The remaining two complex cells were somewhat different from those previously shown. The cell drawn in Figure $5 \mathrm{~A}$ was located near the bottom of layer 6 . It gave off small basal and apical dendritic branches in layers 6 and 5, then the apical dendrite took a straight course to layer $2+3$, where it bif urcated, with each limb nearing the pia. The axon ramified thickly through layers 5 and 6 while a rare process entered layer 4. Only one collateral traversed the depth of the granular layer to end at the upper border. An unusual pyramidal cell was located in lower layer 6 , Figure $5 B$. Its basal dendrites (some too pale to trace) were directed horizontally, and its apical dendrite reached layer 5. The axons rambled for nearly a millimeter at each side of the soma. The majority of the collaterals took a horizontal course after leaving one of the principal trunks. The many short branches that fringed the main processes indicated a high degree of connectivity throughout the arbor. The thickest bundle of fibers ran along the top of layer 5; a substantial meshwork spread though layer 6 as well. Additional projections included a central spray of terminals shot from layer 4 to layer $2+3$ and sparser collaterals in the middle of layer 4 and its upper border. Neither of the cells drawn in Figure 5 seemed to have axons that exited area 17.

\section{DISCUSSION}

Layer 6 of the cat visual cortex includes two physiological classes of neuron, simple and complex. Simple cells are restricted to the upper tier of the layer, whereas complex cells populate its full thickness (Gilbert, 1977). It had previously been thought that layer 4 was the common target of all the pyramidal cells in the layer 6 (Gilbert and Wiesel, 1979; Martin and Whitteridge, 1984; McGuire et al., 1984). We have found a novel projection from 
A

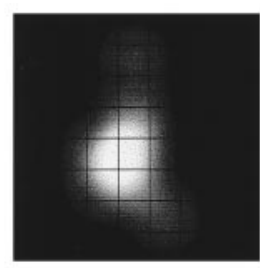

B

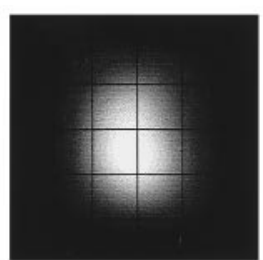

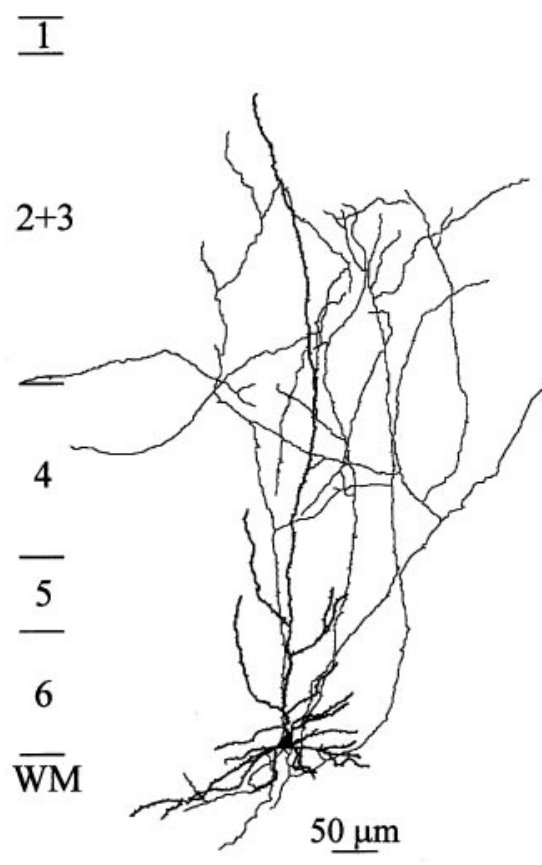

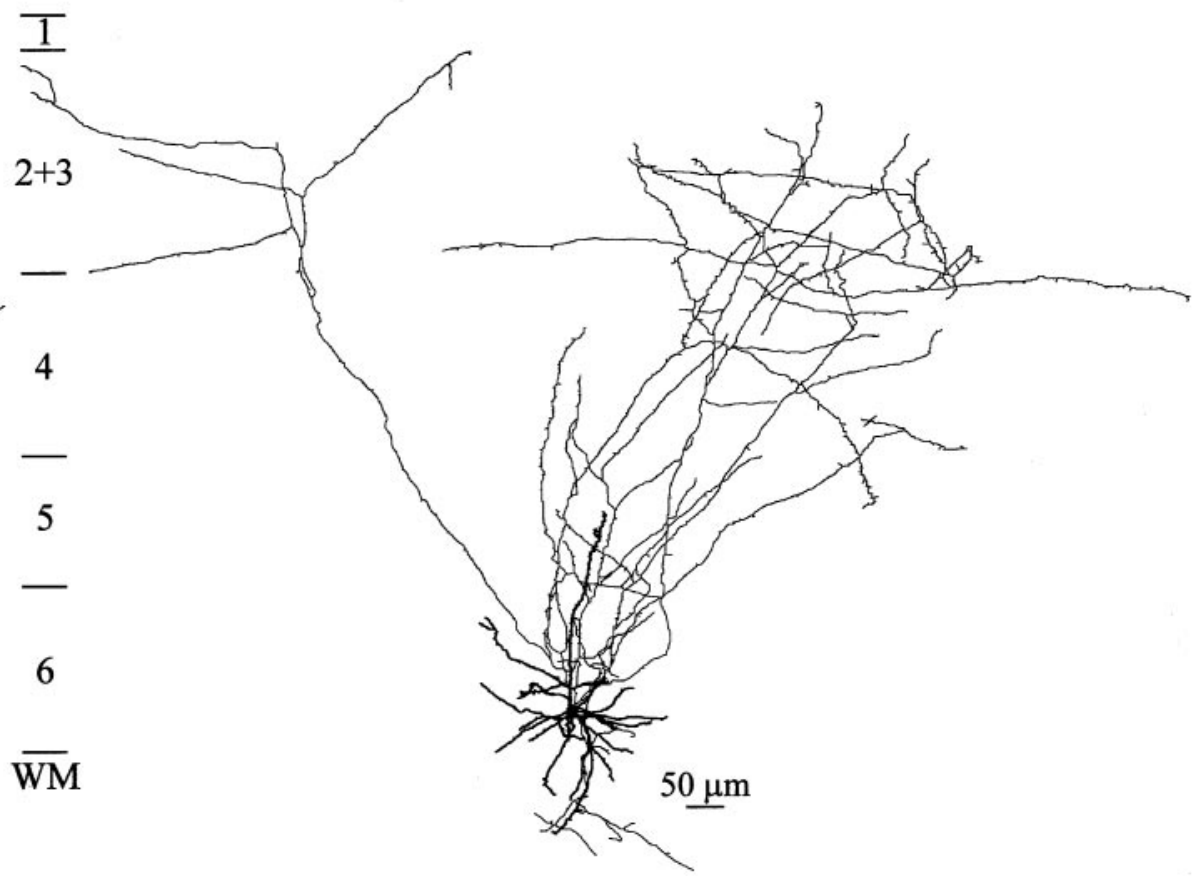

Figure 3. Complex cells in layer 6 that direct their densest output to the lower aspect of the superficial layers. Both cells were located in lower layer 6 and sent much of their output to the border between layers 4 and $2+3$, and lower layer $2+3$. The cell drawn in $B$ gave off prominent collaterals that traveled outside the home column to synapse in the superficial layers. Neither cell seemed to project beyond the white matter. Grid spacing was $0.85^{\circ}$; both maps were constructed from responses to dark stimuli because those alone were effective. Intracellular records from the cell pictured in $B$ are seen in Figure $1 B$

layer 6 by which some complex cells direct their output to the superficial layers. Hence, the functional diversity of layer 6 is reflected in distinct interlaminar patterns of connectivity.

\section{Intracortical connectivity}

\section{Intracolumnar connections}

Our principal finding is that complex cells in layer 6 send much of their output to regions populated by other complex cells, that is, to layers $2+3$ and 5. Moreover, this complex cell pathway is distinct from the one made by simple cells, which supplies dense input to layer 4 (Gilbert and Wiesel, 1979; Martin and Whitteridge, 1984; Fig. 2 this study). Six of the eight complex cells studied projected to the superficial layers. Of these, four preferred the upper aspect of layer $2+3$, and two preferred the lower tier. The remaining cells shared a preference for the infragranular layers. It seems reasonable to conclude that the superficial layers receive strong input from layer 6, although our sample remains too small to permit an exact estimation of the relative weight of ascending input that each layer or sublamina receives.

It is important to mention that not every complex cell in layer 6 favors layers containing other complex cells. McGuire et al. (1984) illustrate two complex cells whose projection patterns resemble those made by simple cells. Complex cells fall into two groups, based on their station in the cortical microcircuit: first order cells receive substantial direct input from the thalamus and second order cells do not (Hoffman and Stone, 1971; Bullier and Henry, 1979; Ferster and Lindström, 1983). In a study of the superficial layers, we recently reported that first and second order complex cells have distinct synaptic physiologies (Hirsch et al., 1997). That is, the visual responses of first order complex cells, like those of simple cells, reliably capture the pattern of thalamic input. By contrast, the behavior of second order cells is variable and unpredictable. The response patterns of the layer 6 complex cells included in the current study resemble the records made from second order cells. Perhaps McGuire et al. (1984) recorded from a different physiological population of layer 6 complex cells, one that receives substantial direct input from the thalamus. In keeping with this idea, the complex cells illustrated in McGuire et al. (1984), like all layer 6 simple cells labeled in vivo (Gilbert and Wiesel, 1979; Martin et al., 1984; Fig. 2), had basal and apical dendritic branches that ramified within upper layer 6 and layer 4 , where the fibers from the dorsal layers of the lateral geniculate terminate. The complex cells that we labeled branched less frequently in these regions.

\section{Extracolumnar projections}

In addition to their role in local processing, projections from layer 6 appear to convey information across visual space. Four of the complex cells we filled sent collaterals outside of their own column to form superficial clusters in adjacent zones. These 
A
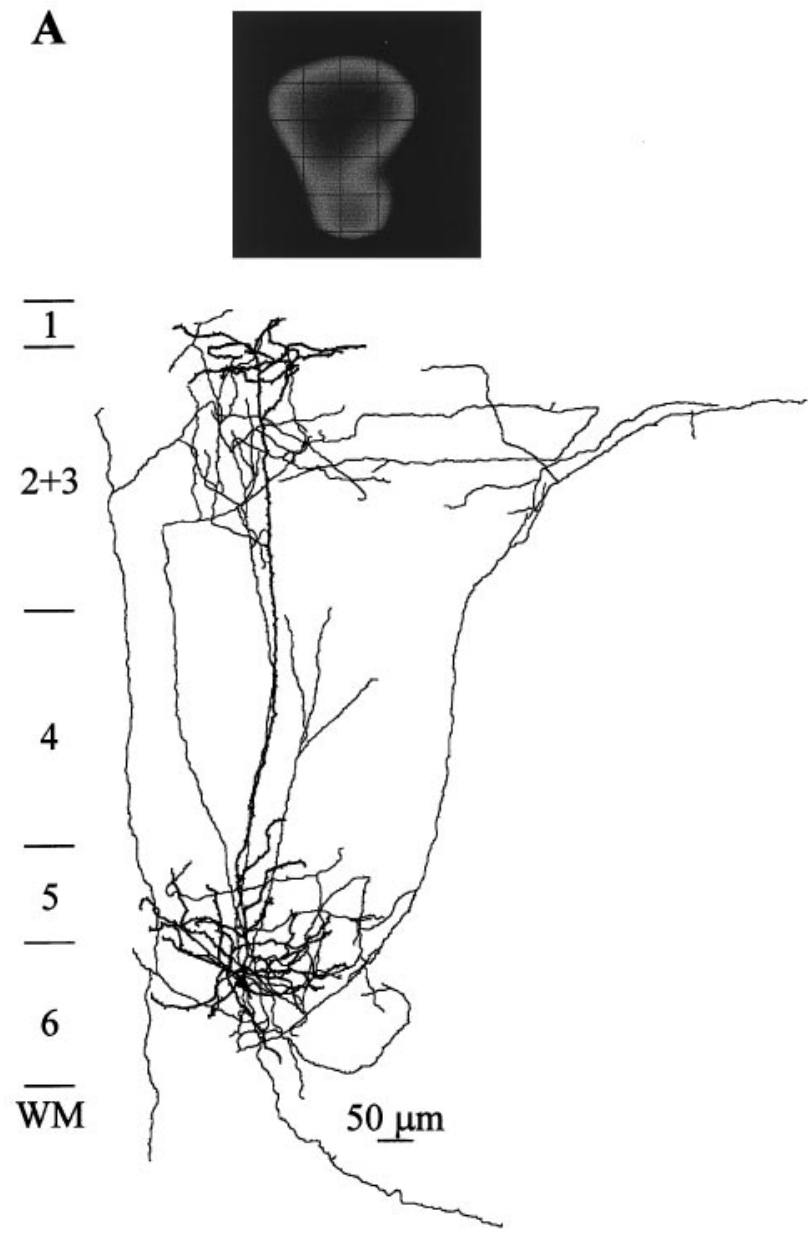

B

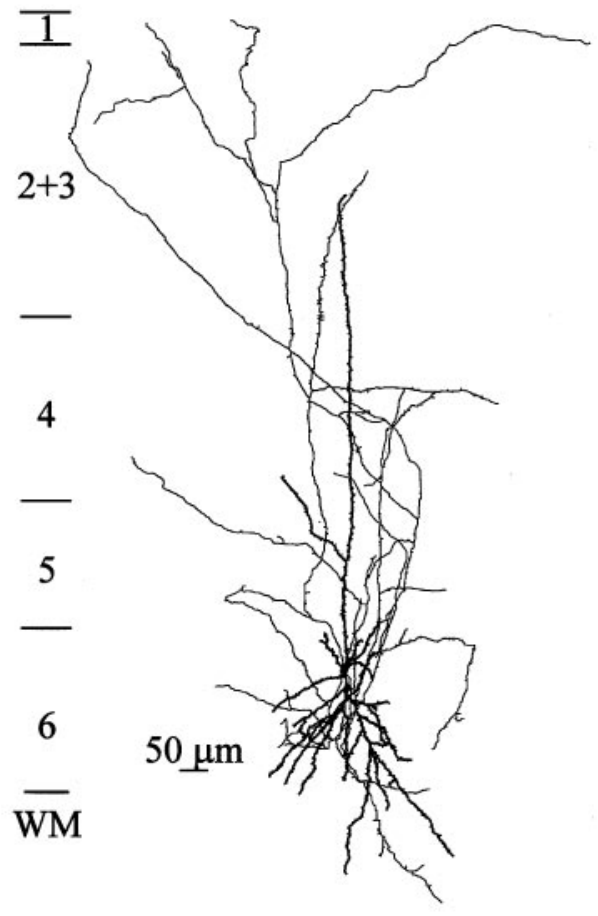

Figure 4. Complex cells in layer 6 whose projections target the upper tier of the superficial layers. The cell drawn in $A$ projected densely to the top half of the superficial layers. The projection included a dense axonal arborization in vertical register with the apical dendrite and a prominent secondary cluster that lay outside the home column. The receptive field map shows responses to dark stimuli; it has an inverse shading pattern to indicate that the net response was inhibitory rather than excitatory (responses to bright stimuli were weak and are not shown); grid spacing was $0.85^{\circ}$. The cell drawn in $B$ also had axon collaterals that reached the pia. This neuron failed to respond to the flashed squares and was mapped by hand with moving light bars. Each of these cells appeared to leave area 17.

clusters were comparable in size and spacing to those made by the horizontal connections that course within layers 5 and 2+3 (Gilbert and Wiesel, 1979, 1983; Martin and Whitteridge, 1984; Gilbert and Wiesel, 1989); albeit the intralaminar collaterals span larger distances (Gilbert and Wiesel, 1983).

Simple cells in layer 6 are also known to direct collaterals that terminate in layer 4, at a distance from the home column (Martin and Whitteridge, 1984; Katz, 1987). We have found evidence of another extracolumnar path, a simple cell that sent lateral connections to layer 6 itself (Katz, 1987). This finding complements the previous observation of a layer 4 simple cell that sent horizontal collaterals in layer 6 (Hirsch et al., 1995). Hence, there appears to be an interlaminar feedback circuit by which simple cells integrate information across cortical columns. This circuit may help to build the long, simple receptive fields occasionally encountered in layer 4 (Jagadeesh and Ferster, 1990) and layer 6 (Gilbert, 1977; Grieve and Sillito, 1991, 1995).

\section{Lamination in cat cortex}

In the primate and tree shrew, fine-grained laminar subdivisions are obvious even from the distribution of cell bodies. This is not the case for the cat. The sublaminar preferences in axonal pro- jection seen in this study, together with illustrations provided by others (Gilbert and Wiesel, 1979, 1983; Lin et al., 1979; Martin and Whitteridge, 1984), indicate that the cat has a higher degree of laminar organization than is evident from the cytoarchitecture alone. As yet, however, it is not clear that the position of a given cell in the depth of layer 6 predicts the sublaminar preference of its output.

\section{Subcortical connectivity Claustral targets}

Cells in layer 6 are known to project to the visual claustrum (LeVay and Sherk, 1981; Katz, 1987); many of these have long apical dendrites that reach layer 1 . Physiological studies show that corticoclaustal cells have simple receptive fields (Grieve and Sillito, 1995). Given that the only cells we labeled that had long dendrites were complex, it is unlikely that we recorded from claustral projecting cells, which make up 3-5\% of the layer 6 population.

\section{Thalamic targets}

In cat, $\sim 50 \%$ of the cells in layer 6 project to the geniculate; these are scattered through the full depth of the layer (Gilbert and 
A

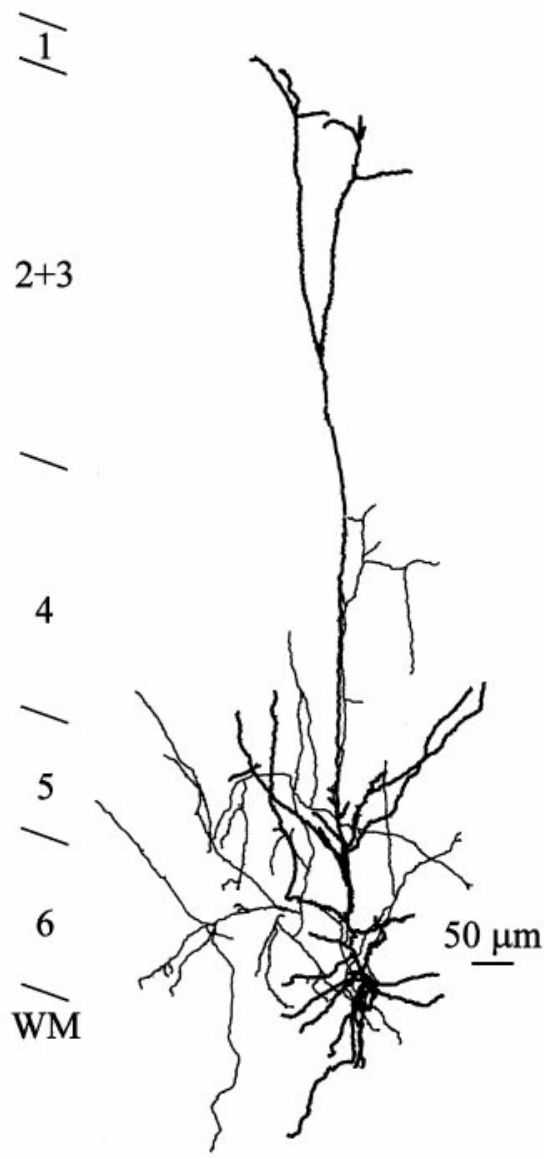

B
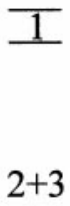

4

$4=$

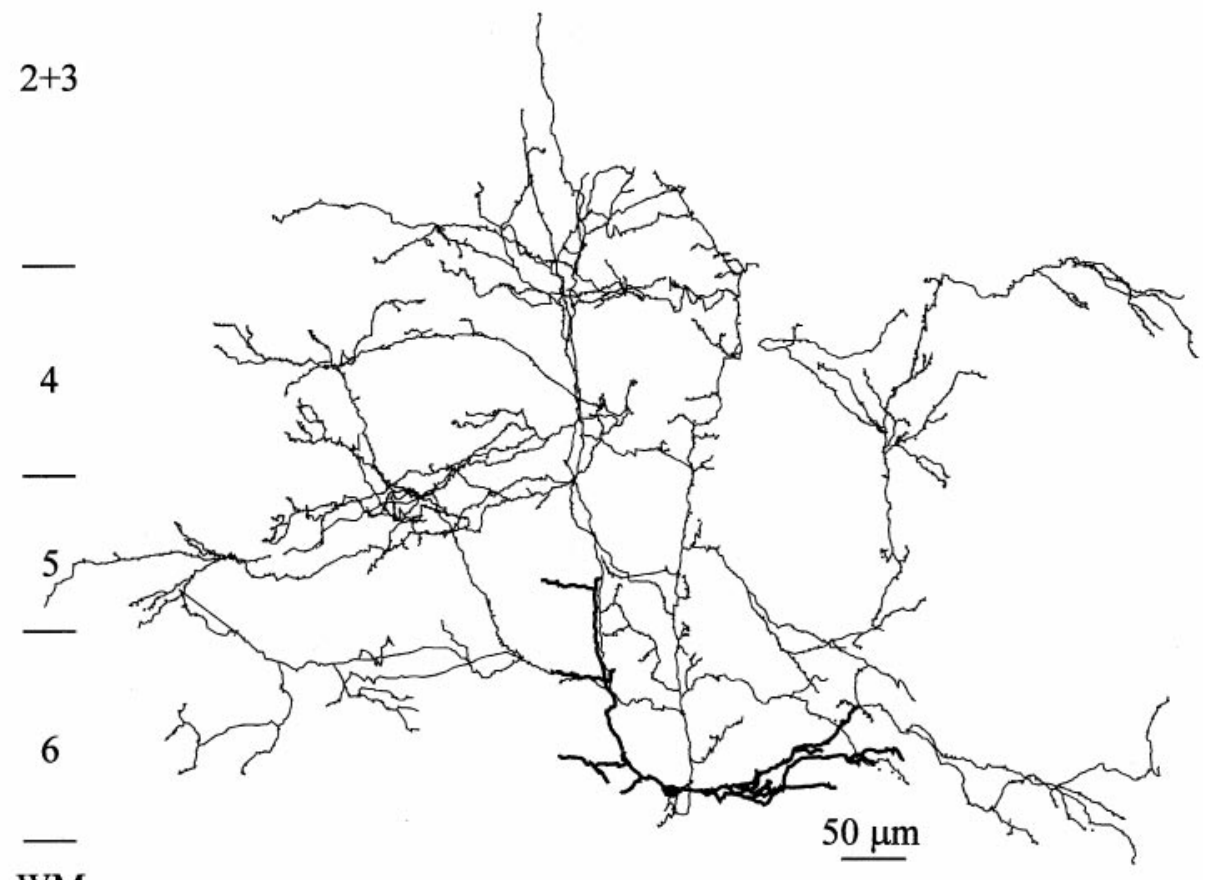

6

WM

Figure 5. Layer 6 complex cells that terminate most heavily in the infragranular layers. Although these two cells were different in many regards, they shared a preference for layers 5 and 6 . Neither seemed to project beyond area 17 . The cell seen in $A$ did not respond to flashed stimuli and was mapped by hand with moving light bars. The map in $B$ was constructed from off responses because bright stimuli were not effective; grid spacing was $0.85^{\circ}$.

Kelly, 1975; McCourt et al., 1986; Katz, 1987), and most of these have simple receptive fields (Grieve and Sillito, 1995). Katz (1987) characterized two types of geniculate projecting cells in vitro. The most common type had dendrites that extended long branches in layer 4 and resembled the simple cells that we and others have filled (Gilbert and Wiesel, 1979; Martin and Whitteridge, 1984; Fig. 2). The other class of corticothalamic cell had sparse apical dendrites that rose no further than layer 3 (presumably the superficial axonal arbors were severed when the slices were cut); these recall one of the complex cells we stained (Fig. $4 B)$. Thus, it appears that our sample included both simple and complex geniculocortical cells.

\section{Comparative anatomy}

Results of anatomical studies in other species give the sense that parallel ascending and descending projections from layer 6 are phylogenetically preserved features of the mammalian visual pathway. Moreover, there is a certain reciprocity in the flow of information between the cortex and thalamus. In one circuit, cells in upper layer 6 direct some axonal collaterals up to layer 4 and others down to the dorsal layers of the geniculate: there, relay cells project back to the upper subtier of layer 6 and to layer 4 (rat, Burkhalter, 1989; galago, Conley and Raczkowski, 1990; macaque, Lund et al., 1975, 1979; Fitzpatrick et al., 1985, 1994; Wiser and Callaway, 1996). A second group of cells, at the base of layer 6 (rat, Burkhalter, 1989; Boursassa and Deschenes, 1995; galago, Conley and Raczkowski, 1990) or distributed throughout its depth (macaque, Fitzpatrick et al., 1985; Wiser and Callaway, 1996) provides ascending input to the supragranular layers and descending axons to the ventral and koniocellular layers of the geniculate and extrageniculate nuclei (for review, see Lund, 1988; Casagrande, 1994; Fitzpatrick, 1996; Callaway, 1998). These thalamic divisions project back to the supragranular layers in turn (rat, Bourassa and Deschenes, 1995; galago, Conley and Raczkowski, 1990; macaque, Fitzpatrick et al., 1994). The divergence in the input and output of layer 6 is best appreciated in the tree shrew. There, upper layer 6 targets the granular layers and the specific subset of geniculate laminae that supply them. A correspondent feedback circuit links lower layer 6 with the supragranular layers and with the remaining geniculate laminae and pulvinar (Usrey and Fitzpatrick, 1996). 


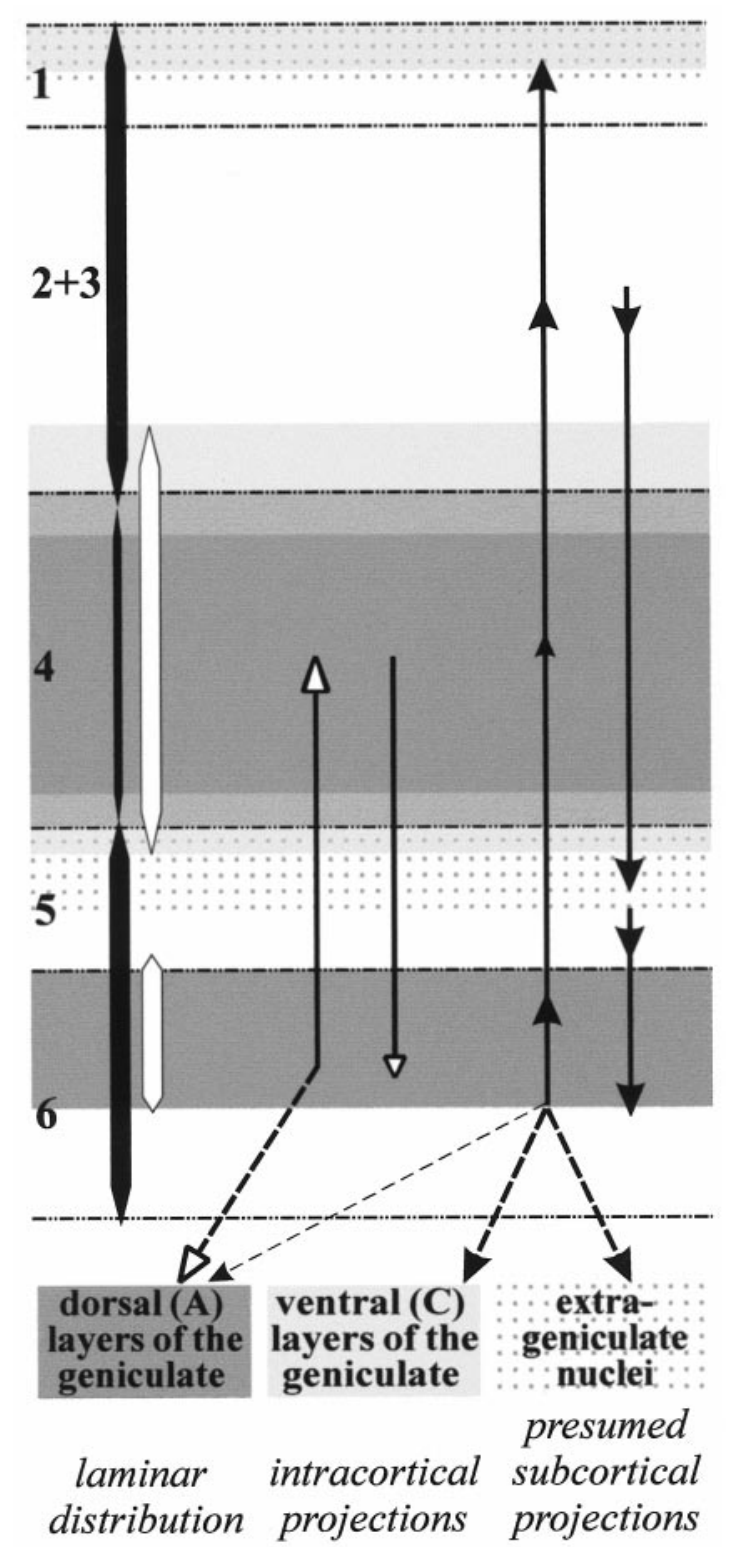

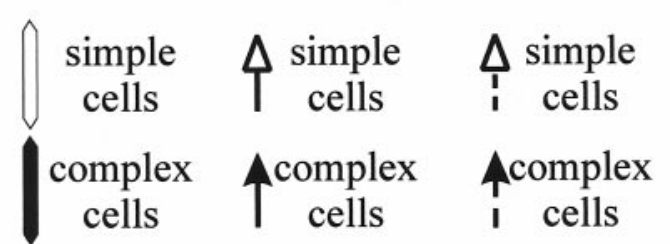

Figure 6. Thalamocortical feedback circuits involving the simple or the complex cells of layer 6 . The extent and weight of the simple (white) and complex (black) cell populations in each cortical layer are indicated by the length and width of the pointed bars at the left of the diagram. The major intracortical pathways are denoted by arrows with solid shafts and presumed descending projections are represented by arrows with dotted shafts. Open arrowheads indicate projections by simple cells, and filled arrows depict projections by complex cells. Thalamorecipient cortical zones are shaded. Dark gray codes regions contacted by the A layers of the lateral geniculate nucleus, light gray shows the projection from the $\mathrm{C}$ laminae, and stippling denotes input from extrageniculate nuclei such as the pulvinar and medial interlaminar nucleus.

\section{Information flow in the projections to and from layer 6 in cat}

Taking the earlier studies (Lund and Boothe, 1975; Lund et al., 1975; Gilbert and Wiesel, 1979; McGuire et al., 1984; Martin and Whitteridge, 1984; Fitzpatrick et al., 1985, 1994; Burkhalter, 1989; Conley and Raczkowski, 1990; Casagrande, 1994; Bourassa and Deschennes, 1995; Sawatari and Callaway, 1996; Usrey and Fitzpatrick, 1996; Wiser and Callaway, 1996) together with our own suggests a pattern of ascending and descending projections from layer 6 that is outlined in a summary diagram (Fig. 6). The projections are divided into two, loosely parallel feedback circuits. One involves the layer 6 complex cells that project to laminae 5 and $2+3$ (Fig. 6, filled arrows). These cells receive input from the ventral layers of the lateral geniculate and the extrageniculate nuclei; subcortical information arrives directly via the apical dendrites or is relayed by overlying complex cells (LeVay and Gilbert, 1976; Miller et al., 1980; Bullier et al., 1984). The path is closed by the descending projections from the layer 6 complex cells to the same thalamic sources. A second loop (open arrows) interconnects the dorsal layers of the geniculate and their principal cortical targets (simple cells and, perhaps, a subgroup of complex cells) (Gilbert and Wiesel, 1979; Robson, 1983; Boyapati and Henry, 1984; McGuire et al., 1984; Humphrey et al., 1985; Ferster, 1990; Ahmed et al., 1994; Grieve and Sillito, 1995; Murphy and Sillito, 1996). The two pathways overlap to an extent; one clear example is that the complex cells that project to the superficial layers provide some input to layer 4. A larger sample of layer 6 cells is required to understand exactly the pattern of information that these two circuits exchange.

The effect of the projection from layer 6 complex cells to the superficial layers remains to be explored. The axons that ascend from layer 6 to layer 4 synapse selectively with dendritic shafts (McGuire et al., 1984; Somogyi, 1989; Ahmed et al., 1994) and appear to contact a higher proportion of smooth cells (McGuire et al., 1984; cf. Ahmed et al., 1994) than do other cortical pathways; these, by and large, favor dendritic spines (McGuire et al., 1991; Johnson and Burkhalter, 1996). Hence, although the synapses made by the layer 6 pyramids are themselves excitatory (Ferster and Lindström, 1985), they have the potential to exert strong inhibitory influence in layer 4 via smooth interneurons (McGuire et al., 1984; Bolz and Gilbert, 1986; Hirsch, 1995). We hope to learn if the projection from layer 6 to the superficial laminae shares the same target preferences as the counterpart path to layer 4 .

\section{REFERENCES}

Ahmed B, Anderson JC, Douglas RJ, Martin KM, Nelson JC (1994) Polyneuronal innervation of spiny stellate neurons in cat visual cortex. J Comp Neurol 341:39-49.

Bolz J, Gilbert CD (1986) Generation of end-inhibition in the visual cortex via interlaminar connections. Nature 320:362-365.

Bourassa J, Deschenes M (1995) Corticothalamic projections from the primary visual cortex in rats: a single fiber study using biocytin as an anterograde tracer. Neuroscience 66:253-263.

Boyapati J, Henry G (1984) Corticofugal axons in the lateral geniculate nucleus of the cat. Brain Res 53:335-40.

Bullier J, Henry GH (1979) Laminar distributions of first order neurons and afferent terminals in cat striate cortex. J Neurophysiol 42:1271-1281.

Bullier J, Kennedy H, Salinger W (1984) Bifurcation of subcortical afferents to visual areas 17, 18, and 19 in the cat cortex. J Comp Neurol 228:309-328.

Burkhalter A (1989) Intrinsic connections of rat primary visual cortex: laminar organization of axonal projections. J Comp Neurol 279:171-186. 
Callaway E (1998) Local circuits in primary visual cortex of the macaque monkey. Annu Rev Neurosci 21:47-74.

Casagrande VA (1994) A third parallel visual pathway to primate area V1. Trends Neurosci 17:305-310.

Conley M, Raczkowski D (1990) Sublaminar organization within layer VI of the striate cortex in Galago. J Comp Neurol 302:425-436.

Edwards FA, Konnerth T (1992) Patch-clamping cells in sliced tissue preparations. Methods Enzymol 207:208-222.

Ferster D (1988) Spatially opponent excitation and inhibition in simple cells of the cat visual cortex. J Neurosci 8:1172-1180.

Ferster D (1990) X-and Y-mediated synaptic potentials in neurons of areas 17 and 18 of the cat visual cortex. Vis Neurosci 4:115-133.

Ferster D, Lindström S (1983) An intracellular analysis of geniculocortical connectivity in area 17 of the cat. J Physiol (Lond) 342:181-215.

Ferster D, Lindström S (1985) Synaptic excitation of neurones in area 17 of the cat by intracortical axon collaterals of cortico-geniculate cells. J Physiol (Lond) 367:233-252.

Fitzpatrick D (1996) Functional organization of local circuits in visual cortex: Insights from the study of tree shrew striate cortex. Cereb Cortex 6:329-341.

Fiztpatrick D, Lund JS, Blasdel GG (1985) Intrinsic connections in macaque striate cortex: afferent and efferent connections of lamina 4C. J Neurosci 5:3329-3349.

Fitzpatrick D, Usrey WM, Schofield BR, Einstein G (1994) The sublaminar organization of corticogeniculate neurons in layer 6 of macaque striate cortex. Vis Neurosci 11:307-315.

Gilbert CD (1977) Laminar differences in receptive field properties of cells in cat primary visual cortex. J Physiol (Lond) 268:391-421.

Gilbert CD, Kelly JP (1975) The projections of cells in different layers of the visual cortex. J Comp Neurol 163:81-106.

Gilbert CD, Wiesel TN (1979) Morphology and intracortical projections of functionally identified neurons in cat visual cortex. Nature 280:120-125.

Gilbert CD, Wiesel TN (1981) Laminar specialization and intracortical connections in cat primary visual cortex. In: The Organization of the cerebral cortex (Schmitt FO, Worden FG, Adelman G, Dennis SG, eds), pp 164-190. Cambridge: MIT.

Gilbert CD, Wiesel TN (1983) Clustered intrinsic connections in cat visual cortex. J Neurosci 3:1116-1133.

Gilbert CD, Wiesel TN (1989) Columnar specificity of intrinsic horizontal and corticocortical connections in cat visual cortex. J Neurosci 9:2432-2442.

Grieve KL, Sillito AM (1991) A re-appraisal of the role of layer VI of the visual cortex in the generation of cortical end inhibition. Exp Brain Res 87:521-529.

Grieve KL, Sillito AM (1995) Differential properties of cells in the feline primary visual cortex providing the corticofugal feedback to the lateral geniculate nucleus and visual claustrum. J Neurosci 15:4868-4874.

Hirsch JA (1995) Synaptic integration in layer 4 of the ferret visual cortex. J Physiol (Lond) 481:247-262.

Hirsch JA, Alonso JM, Reid RC (1995) Visually evoked calcium action potentials in cat striate cortex. Nature 378:612-616.

Hirsch JA, Alonso JM, Reid RC, Martinez LM (1997) Differences between the synaptic responses of first and second order complex cells in cat striate cortex. Soc Neurosci Abstr 23:1666.

Hoffman KP, Stone J (1971) Conduction velocity of afferents to cat visual cortex: A correlation with cortical receptive field properties. Brain Res 32:460-466.

Horikawa K, Armstrong WE (1988) A versatile means of labeling: injection of biocytin and its detection with avidin conjugates. J Neurosci Methods 25:1-11.

Hubel DH, Wiesel, TN (1962) Receptive fields, binocular interaction and functional architecture in the cat's visual cortex. J Physiol (Lond) 160:106-154.

Humphrey AL, Sur M, Ulrich DJ, Sherman SM (1985) Projection patterns of individual $\mathrm{X}$ and $\mathrm{Y}$ cell axons from the lateral geniculate nucleus to cortical areas 17 and 18. J Comp Neurol 233:159-189.

Jagadeesh B, Ferster D (1990) Receptive field lengths in cat striate cortex can increase with decreasing stimulus contrast. Soc Neurosci Abstr 16:293.

Johnson RR, Burkhalter A (1996) Microcircuitry of forward and feedback connections within rat visual cortex. J Comp Neurol 368:383-98.
Jones JP, Palmer LA (1987) The two-dimensional spatial structure of simple receptive fields in cat striate cortex. J Neurophysiol 58:1187-1211.

Katz LC (1987) Local circuitry of identified projection neurons in cat visual cortex brain slices. J Neurosci 7:1223-1249.

LeVay S, Gilbert CD (1976) Laminar patterns of geniculocortical projection in the cat. Brain Res 113:1-19.

LeVay S, Sherk H (1981) The visual cortex of the cat. I. Structure and connections. J Neurosci 1:956-980.

Lin CS, Friedlander MJ, Sherman SM (1979) Morphology of physiologically identified neurons in the visual cortex of the cat. Brain Res $172: 344-348$

Lund J (1988) Anatomical organization of macaque monkey striate visual cortex. Annu Rev Neurosci 11:253-288.

Lund JS, Boothe R (1975) Interlaminar connections and pyramidal neuron organization in the visual cortex, area 17 , of the macaque monkey. J Comp Neurol 164:287-303.

Lund JS, Lund RD, Hendrickson AE, Bunt AH, Fuchs AF (1975) The origin of efferent pathways from the primary visual cortex, area 17, of the macaque monkey as shown by retrograde transport of horseradish peroxidase. J Comp Neurol 164:287-303.

Lund JS, Henry GH, MacQueen CL, Harvey AR (1979) Anatomical organization of the primary visual cortex (area 17) of the cat. A comparison with area 17 of the macaque monkey. J Comp Neurol 184:599-618.

Malinow R, Tsien RW (1990) Presynaptic enhancement shown by whole-cell recordings of long-term potentiation in hippocampal slices. Nature 346:177-180.

Martin KAC, Whitteridge D, (1984) Form, function and intracortical properties of spiny neurones in striate visual cortex of the cat. J Physiol (Lond) 353:463-504.

McCourt ME, Boyapati J, Henry GH (1986) Layering in lamina 6 of cat striate cortex. Brain Res 364:181-185.

McGuire B, Hornung J-P, Gilbert CD, TN Wiesel (1984) Patterns of synaptic input of layer 4 of the cat striate cortex. J Neurosci 4:3021-3033.

McGuire BA, Gilbert CD, Rivlin PK, Wiesel TN (1991) Targets of horizontal connections in macaque primary visual cortex. J Comp Neurol 305:370-92.

Miller JW, Buschmann MB, Benevento LA (1980) Extrageniculate thalamic projections to the primary visual cortex. Brain Res 189:221-227.

Movshon JA, Thompson ID, Tolhurst DJ (1978) Receptive field organization of complex cells in the cat's striate cortex. J Physiol (Lond) 283:79-99.

Murphy PC, Sillito AM (1996) Functional morphology of the feedback pathway from area 17 of the cat visual cortex to the lateral geniculate nucleus. J Neurosci 16:1180-1192.

Ohzawa I, Freeman, RD (1986) The binocular organization of complex cells in the cat's visual cortex. J Neurophysiol 56:243-259.

Palmer LA, Davis TL (1981) Comparison of responses to moving and stationary stimuli in cat striate cortex. J Neurophysiol 46:260-276.

Robson JA (1983) The morphology of corticofugal axons to the dorsal lateral geniculate nucleus in the cat. J Comp Neurol 216:89-104.

Sawatari A, Callaway EM (1996) Convergence of magno- and parvocellular pathways in layer $4 \mathrm{~B}$ of macaque primary visual cortex. Nature. 380:442-446.

Skottun BC, DeValois RL, Grosof DH, Movshon JA, Albrecht DG, Bonds AB (1991) Classifying simple and complex cells on the basis of response modulation. Vision Res 31:1079-1086.

Somogyi P (1989) Synaptic organization of GABAergic neurons and $\mathrm{GABA}_{\mathrm{a}}$ receptors the lateral geniculate nucleus and the visual cortex. In: Neural mechanisms of perception (Lam DM, Gilbert CD, eds), pp 35-62. Houston: Gulf.

Stühmer W, Roberts WM, Almers W (1983) The loose patch clamp. In: Single channel recording (Sakmann B, Neher E, eds), pp 123-132. New York: Plenum.

Usrey WM, Fitzpatrick D (1996) Specificity in the axonal connections of layer VI neurons in tree shrew striate cortex: evidence for distinct granular and supragranular systems. J Neurosci 16:1203-1218.

Wiser AK, Callaway E M (1996) Contributions of individual layer 6 pyramidal neurons to local circuitry in macaque primary visual cortex. J Neurosci 15:2724-2739. 